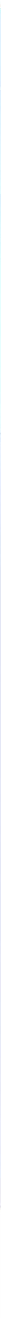




\section{ENTENDENDO E MITIGANDO OS ACIDENTES AMPLIADOS NA} MINERAÇÃO: APLICAÇÃO DE MODELO TEÓRICO-CONCEITUAL PARA GERENCIAMENTO DE RISCO

\section{FERNANDO DISCACCIATI CRUZ* BECK NADER *:*}

RESUMO Os acidentes ampliados recorrentes trouxeram à tona questionamentos acerca das boas práticas na mineração. A dimensão dos danos e a ressonância das vozes das vítimas fomentaram dúvidas sobre a sustentabilidade dos processos mineiros. É possível fazer mineração responsável e produtiva? Quais seriam os papéis e as responsabilidades de protagonistas e coadjuvantes das lamentáveis cenas? Logo, um estudo que busca resgatar a noção dos desastres ampliados mineiros assume relevância para tentar responder estes questionamentos. No plano metodológico, será adotado um modelo de aplicação teórico-conceitual a respeito das técnicas de gerenciamento de risco e análise de acidentes anteriores. Em que os achados indicarão que é possível fazer mineração responsável, produtiva e que seus danos, quando houver, possam ser mitigados.

PALAVRAS-CHAVE acidentes ampliados. gerenciamento de risco. gerenciamento de segurança. modelo de gestão de riscos.

\section{UNDERSTANDING AND MITIGATING MINING MAJOR ACCIDENTS: APPLICATION OF THEORETICAL- CONCEPTUAL MODEL FOR RISK MANAGEMENT}

ABSTRACT Recurring major accidents have raised questions over best practices in mining. The largeness of the damage and the resonance of the victims' voices raised doubts about the sustainability of mining processes. Is possible mining in a responsible and productive way? What would be the roles and responsibilities of the protagonists and assistants in the pitiful scenes? Therefore, a study that seeks to rescue the idea of mining major accidents is relevant to try to answer these questions. At the methodological level, a theoretical-conceptual application model will be adopted regarding risk management techniques and analysis of past accidents. The findings will show that it is possible to have responsible, productive mining and that its damage, if any, can be mitigated.

KEYWORDS major accidents. risk management. safety management. risk management model.

* Engenheiro metalurgista e de segurança do trabalho. Mestre em tecnologia mineral.

E-mail:fernando.discacciati@gmail.com .

** Doutor em engenharia mineral. Professor titular do departamento de engenharia de minas - Universidade Federal de Minas Gerais. consultor, Fellow do Instituto Australiano de Geocientistas; E-mail: beckn@demin.ufmg.br 


\section{Introdução}

$\mathrm{N}$ a atual conjuntura, há uma perplexidade diante da sociedade, brasileira e glode seus ativos, com influências maiores sobre seus stakeholders. É fato que os eventos indesejados, com impactos que se amplificam no espaço e no tempo, denominados acidentes ampliados, ocorridos em solo brasileiro, abalam a confiança de todo o sistema de prevenção e controle de riscos. Além disso, tais ocorrências contribuem diretamente para essa hesitação do corpo social, sendo três rompimentos de barragens de rejeitos de mineração, com vítimas fatais e devastação ambiental, em um intervalo de pouco mais de quatro anos.

Trata-se, primeiramente, do rompimento da barragem BI da mineradora Herculano, em Itabirito (MG), no dia Io de setembro 20I4, vitimando três pessoas, ferindo outras sete e impactando ambientalmente o rio das Velhas.

O rompimento do barramento de Fundão, da mineradora Samarco, no dia 5 de novembro de 2015 , compreendido como o maior desastre socioambiental da história brasileira e o maior do mundo envolvendo barragens de rejeitos, causou a destruição total dos distritos de Bento Rodrigues e Paracatu de Baixo em Mariana (MG). Ademais, a catástrofe vitimou I9 pessoas e deixou cidades alastradas de dor e incertezas sobre os seus destinos, visto que a mineração é a base econômica da região em caráter secular.

Não obstante, tivemos, no dia 25 de janeiro de 2019, o rompimento da barragem

1 Laboratório de Informação em Saúde

(LIS)/Instituto de Comunicação e Informação Científica e Tecnológica em Saúde (ICICT/Fiocruz).
Bi da mina de Córrego do Feijão, sob responsabilidade da VALE S.A., no município de Brumadinho (MG), vitimando 270 pessoas - sendo II desaparecidos até o momento da confecção do estudo. A onda de rejeitos de mineração atingiu o rio Paraopeba, causando danos ambientais e impactos sociais em 3.485 pessoas de imediato, aproximadamente ı०\% da população de Brumadinho, segundo dados do censo demográfico de 20IO, elaborado pelo Núcleo de Geoprocessamento (LIS/ICICT/Fiocruz), em nota técnica por Barcellos et al. (2019). 
Obviamente, um acidente ampliado acarreta mais impactos na sociedade do que acidentes laborais. Embora não seja o foco dessa análise, trata-se de um outro viés que precisamos debater na mineração e que traremos para esta reflexão. Segundo Candian (20I8), embora haja, nos últimos anos, uma redução significativa na taxa de lesões e acidentes na mineração brasileira, o número e o grau de severidade ainda são altos para os padrões industriais. Em "Health and Safety in Brazilian Mines: A Statistical Analysis", apresentado por Campos et al. (2019), é exposto que a indústria extrativa é a quarta atividade em relação à taxa de incidência de acidentes laborais entre os setores econômicos brasileiros e a primeira na taxa de mortalidade.

É fato, também, que acidentes industriais ampliados e laborais não são especificidades do serviço mineiro. Tal afirmação é comprovada pelo fato de termos uma lamentável e extensa lista de acidentes maiores em setores e regiões diversas, tais como a Tragédia de Bhopal, na Índia, em 2 de dezembro de I984, que foi considerada como o pior acidente químico do mundo. Contudo, apesar de haver discrepâncias consideráveis em relação aos números do desastre, Evan e Manion (2002) relatam que o acidente tenha vitimado algo em torno de I4.000 pessoas e uma projeção de mais de 30.000, com danos permanentes à saúde como resultado da intoxicação por gás de Isocianato de Metila (MIC), por ocasião do vazamento de 4I toneladas de um tanque de armazenamento da indústria norte americana Union Carbide Corporation. Números oficiais do banco de dados Major Hazard Incident Data Service (MHIDAS) registram 2.00I fatalidades, de acordo com Carol, Vilchez e Casal (2005).

Na atual cidade fantasma de Pripyat, na Ucrânia, em 26 de abril de I986 acontecia o pior desastre nuclear da história. Após a explosão do reator 4 da usina nuclear soviética de Chernobyl, de acordo com o International Programme on the Health Effects of the Chernobyl Accident (IPHECA), houve uma radioatividade liberada em 200 vezes maior que a das bombas atômicas de Hiroshima e Nagasaki combinadas. Oficialmente são 3I óbitos diretos da tragédia. Em contrapartida, a Organização Mundial da Saúde (OMS) diz algo em torno de 9.000 vítimas fatais por males associados à radiação. Para evidenciar o impacto do desastre dentro do contexto socioambiental, político e científico, Freitas (2000), no livro Acidentes industriais ampliados: desafios e perspectivas para o controle e a prevenção, expõe como a tragédia de Chernobyl traduz a consequência de um acidente ampliado: 
A importância dos acidentes ampliados está contida no fato, amplamente demostrado no caso de Chernobyl, de que pela primeira vez o homem, por meio de atividades concebidas para garantir seu próprio progresso e nível de vida, pode produzir um nível de destruição capaz de matar grandes números de civis; abalar os alicerces da estrutura econômica e política não apenas do país onde o acidente foi produzido mas também de seus vizinhos; ameaçar em uma escala massiva as capacidades reprodutivas humanas e resultar em enormes danos ao meio ambiente (FREITAS, 2000, p. I08).

Sabemos que nenhum empreendimento é projetado e gerenciado para falhar, colapsar e causar desastres e danos à vida humana e ao meio-ambiente. Entretanto, a engenharia, dentro de suas limitações tecnológicas, projeta com margens de segurança estabelecida, através de conhecimentos empíricos, porém, sem contemplar, em sua plenitude, todas as possibilidades de ocorrências de falhas e colapso. Essa incidência, aliada às lacunas de gerenciamento de ativos, não desenvolvimento de novas tecnologias e soluções, sistemas de fiscalização ineficientes, baixo investimento no setor e morosidade nas ações governamentais, potencializa os acidentes laborais e desastres ampliados.

Diante desses cenários e da dubiedade da confiança social sobre a segurança dos processos mínero-metalúrgicos e a indispensabilidade da mineração para o desenvolvimento e a manutenção da vida, surgem os objetivos deste artigo, cujo objetivo é responder - por meio de um modelo teórico-conceitual, baseado em técnicas de gerenciamento de risco, análise de eventos passados, suas correlações, causas raízes e lições aprendidas - que sim, é possível fazer mineração responsável, produtiva, com ativos em classe mundial e cujos danos, quando houver, possam ser mitigados.

\section{Da compreensão dos acidentes ampliados industriais}

A definição acerca do conceito de acidente industrial ampliado aqui apreciado advém de Freitas et al. (2000, p. I7), que definem esses acidentes como: “Eventos agudos com potencial para causar simultaneamente múltiplos danos, sociais, ambientais e à saúde física e mental dos seres humanos expostos". Considera-se, portanto, que a caracterização dos acidentes ampliados não se trata apenas do potencial de vitimização, 
mas também da gravidade e da dimensão dos seus limites espaciais, ultrapassando as fronteiras das instalações industriais, como bairros, cidades, estados e países. Procede-se também da particularidade temporal dos eventos, cujos danos se ampliam futuramente na população e no meio exposto, como carcinogênese, mutagênese, impactos socioeconômicos, psicológicos e ambientais.

Um segundo ponto de vista, e talvez o pioneiro na conceituação de acidentes ampliados, seria o da Diretiva do Conselho (I982, p. 229), até então Comunidades Europeias, que os classificam como “acidentes maiores”, derivados de:

uma ocorrência, tal como uma emissão, incêndio ou explosão envolvendo uma ou mais substâncias químicas perigosas, resultando de um desenvolvimento incontroláveis no curso da atividade industrial, conduzindo a sérios perigos para o homem e o meio ambiente, imediatos ou a longo prazo, internamente e externamente ao estabelecimento.

Observa-se que, embora haja um esforço na evolução do conceito ao longo das atualizações da Diretiva, ainda não há a consideração de outros impactos além dos já citados, como propriedade, saúde física, meio ambiente e finanças. Nota-se também o enfoque nas substâncias químicas perigosas e os meios de impactos: emissão, incêndio e explosão. Dessa forma, e buscando uma abrangência maior do conceito, consideraremos a proposta de Freitas et al. (2000).

A evolução dos acidentes industriais ampliados relaciona-se com o desenvolvimento dos processos manufaturados e o incremento da demanda de consumo, em nível internacional e brasileiro, advindo do cenário pós-Segunda Guerra Mundial. Em decorrência do crescimento econômico, aliado à inserção no mercado de novos materiais e produtos e avanços nos meios tecnológicos, expandiu-se o parque industrial, assim como o aumento das dimensões e da complexidade das instalações industriais.

O Programa das Nações Unidas para o Meio Ambiente, United Nations Environment Programme (UNEP), já destacava, em I992, que a expansão das operações industriais e dos meios manufatureiros de produção, armazenamento e transporte de substâncias químicas em nível global possibilitaria impactos no cenário socioambiental, através do aumento da exposição de trabalhadores, comunidades e ambiente, inseridos na perspectiva de riscos e perigos industriais (UNEP, I992).

Aliados ao desenvolvimento dos processos manufaturados e à expansão das indústrias, destacam-se alguns fatores que intensificam o risco e os impactos dos acidentes 
ampliados, sendo o primeiro a localização de comunidades em área de exposição e risco com as indústrias. O incêndio na Vila Socó, em Cubatão (SP), em ig84, que sensibilizou o Brasil com números oficiais de 93 óbitos e extraoficial superior a 500 vítimas fatais, é um exemplo das ocupações muitas vezes desordenadas que aumentam os danos em uma tragédia ampliada. Em segundo, tem-se as limitações tecnológicas e de conhecimento parcial de perigos, aspectos e impactos das operações e dos processos de alto risco. Como destaque, pode-se mencionar a explosão de Oppau, na Alemanha, que já em I92I demonstrava a importância de conhecer todos os perigos e os aspectos das particularidades tecnológicas do processo de fabricação. A explosão ocorreu em uma fábrica de fertilizantes da Badische Anilin-und Soda-Fabrik (BASF) quando um silo de armazenamento, com 4.500 toneladas de uma mistura de sulfato de amônia e nitrato de amônia, explodiu após operação de desobstrução do material com uso de dinamite, matando 56r pessoas e ferindo outras I.952.

Por fim, mas não menos importante, há a capacidade de resposta imediata e post mortem dos eventos. Os rompimentos consecutivos dos barramentos de alteamento para montante das mineradoras em solo brasileiro exemplificam as deficiências governamentais, empresariais e de engenharia nas tomadas de decisão e gerenciamento de risco dos ativos.

O fenômeno de expansão do parque industrial e das capacidades operantes, aliados

20 Pondicherry University Process-industry Accident Database (PUPAD), desenvolvido em 2010 por Tauseef, Abbasi e Abbasi, do centro para controle de poluição e engenharia ambiental da Universidade de Pondicherry, na Índia, tem como objetivo estabelecer um banco de dados de código aberto $e$ abrangente, para fomentar o intercâmbio de lições aprendidas e aprimorar a prevenção e as mitigações dos efeitos acidentes através de um compilado de análises dos eventos anteriores. aos fatores aqui citados, potencializa a ocorrência de eventos acidentais em grandes amplitudes na indústria, destacando-se, em um primeiro momento, os eventos em processos químicos de manufatura. O Gráfico I traduz o registro, entre os anos de I94I e 20I4, do sistema de notificação de acidente na indústria de processo, Pondicherry University Process-industry Accident Database (PUPAD), que diz respeito a um banco de dados de código aberto para ajudar na análise de acidentes (TAUSEEF; ABBASI; ABBASI, 20II). Dos 9.435 eventos registrados no período, observamos 55.499 óbitos, com destaque para a década de I980, com acidentes como o de Bophal, na Índia, e as explosões de San Juan Ixhuatepec, no México, que intensificam os números. Ademais, cabe ressaltar que por mais eficiente e completo que seja o banco de notificações, haverá sempre registros pendentes em sua base. Como consequência, o número global é notavelmente maior que o observado nesta análise. 
Gráfico 1 -Ocorrências de eventos notificados no PUPAD entre 1941 e 2014.

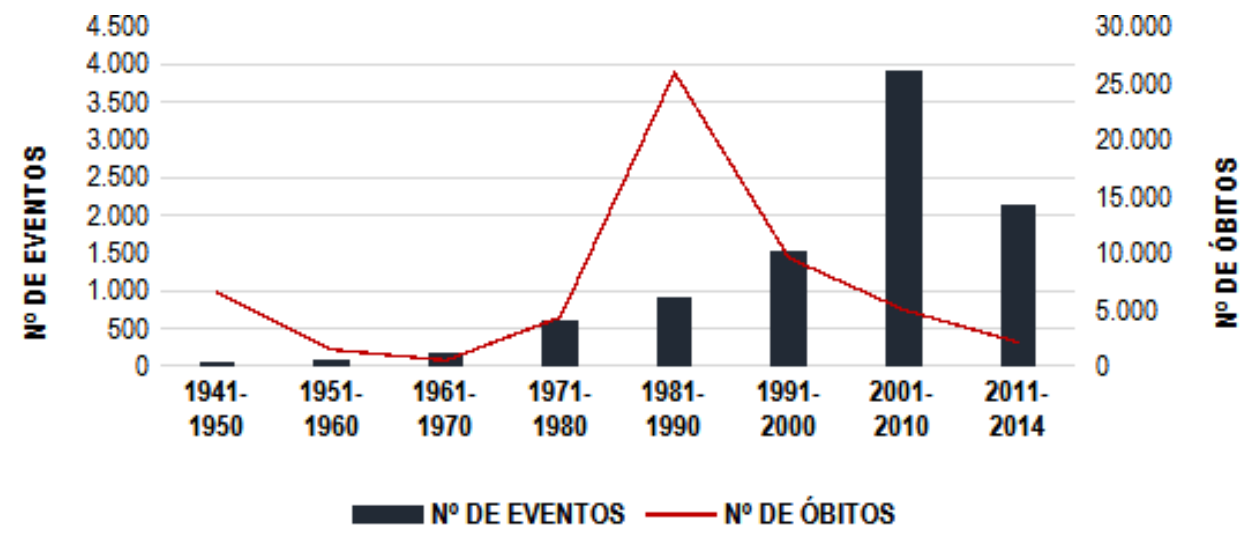

São registrados os tipos de acidente, tipos de instalação, substâncias envolvidas, causas do acidente e motivações iniciais. Fonte: elaborado pelos autores (2020) com base no PUPAD

Do total de 6.829 eventos que foram notificados de acordo o tipo de indústria de ocorrência, como verifica-se no Gráfico 2, entre os que tiveram maior quantidade de frequência, encontram-se em primeiro lugar os eventos ocorridos em indústrias de produtos químicos, com 2.633 acidentes $(38,6 \%)$, em segundo lugar estão as indústrias petroquímicas e refinarias de petróleo, com 949 eventos registrados no PUPAD, $(\mathrm{I} 3,9 \%)$, seguidas pelo setor de armazenamento de produtos perigosos, 5 Io registros $(7,5 \%)$ entre os anos de i899 e 2014 .

Gráfico 2 -Acidentes ampliados registrados no PUPAD entre 1899 e 2014 por tipo de indústria

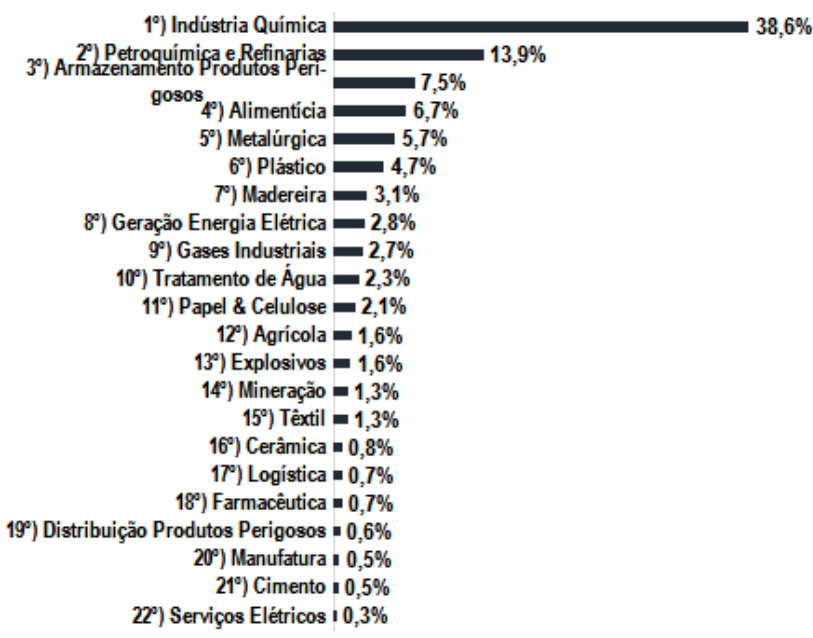

Base de dados referente a 6.829 itens notificados com o tipo de indústria. Fonte: elaborado pelos autores (2020) com base no PUPAD 
Embora os dados apresentados provenham de um compilado de fontes (PUPAD), há limitações amostrais e foco no parque industrial de processos químicos, que não representa a magnitude global existente. Podem-se auferir algumas conclusões bastante gerais: as indústrias que mais concentram acidentes ampliados são: indústria de produtos químicos, petroquímica e refinarias de petróleo, sendo as atividades de produção, manuseio e transporte as responsáveis pela maioria dos registros. Via de regra, explosões e incêndios são os principais causadores dos óbitos imediatos de grande número de pessoas (trabalhadores e comunidades próximas). Como já trazido por Freitas et al. (2000), não significa que os acidentes envolvendo emissões, mesmo através da combustão, em transporte ou produção sejam menos graves. Porém, caracterizam-se mais por impactos sobre a saúde no longo prazo, atingindo, em termos quantitativos, igualmente trabalhadores e comunidades.

\subsection{Do cenário mineiro para acidentes ampliados}

Conforme Freitas et al. (2000) expõem, os grandes acidentes no desenvolvimento da civilização industrial foram produzidos no processo de mineração de carvão, portanto, parte de suas vítimas são os próprios mineiros. Os acidentes ampliados de Courrières, Monoongha e Senghenydd são exemplos clássicos deste cenário.I

De acordo com os dados do PUPAD, acidentes envolvendo diretamente a indústria da mineração correspondem a 89 (I,3\%) de um total de 6.829 notificações, sendo inexistente registros em solo brasileiro. Decerto, a observância da construção deste memorial não contempla uma amostra fidedigna das operações mineiras globais, além disso os registros dos acidentes em mineração estão no espaço temporal entre os anos de 200I e 20I2, não amparando as ocorrências anteriores a data. O Gráfico 3 ilustra o comportamento do contexto mineiro presente no PUPAD. O antagonismo ao analisar a imagem ocorre quando nos deparamos com a advertência de que a mineração não é a mais frequente em termos de eventos ( $4_{4}^{\circ}$ de acordo com o Gráfico 2), entretanto, detém o maior índice de mortalidade: I6,5 óbitos por eventos notificados, cerca três vezes superior ao índice da indústria química, com 5,5 óbitos por evento. 
Gráfico 3 - Índice de mortalidade (óbitos por evento) em relação ao \% total de óbitos totais das indústrias que apresentaram descrição na base de dados PUPAD até 2014

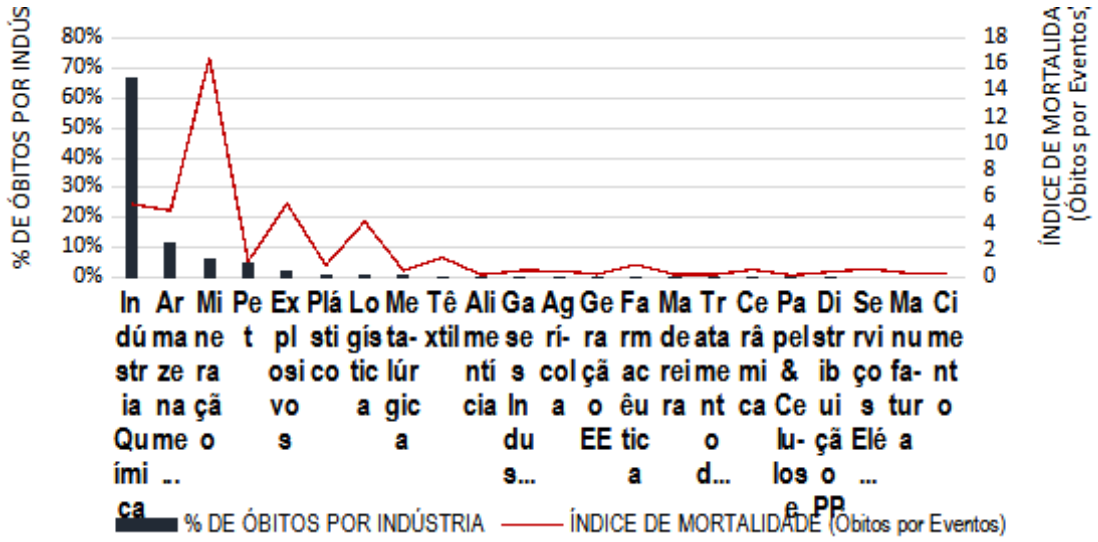

Fonte: elaborado pelos autores (2020) com base no PUPAD

Complementando o PUPAD, citamos o estudo de Lirong et al. (20II), que a fim de obter uma análise direta da mineração, revisar a situação das operações de carvão chinesa e proporcionar informações sobre os principais aspectos acidentais, investigou, somente na mineração de carvão da China, 26 grandes acidentes entre os anos de I949 e 2009, cada um dos quais levou a mais de ıoo óbitos.

Dado as devidas especificidades da mineração de carvão, em sua maioria com operações subterrâneas com alta exposição a gases e poeiras inflamáveis e baixo emprego tecnológico, observa-se que apenas I dos 26 acidentes ampliados na mineração de carvão chinesa, objeto do estudo de Lirong et al. (2009), resultou de um rompimento de barragem. Entretanto, este item, como pode ser analisado na Tabela I, é o maior potencial de óbito por evento, visto que apenas I rompimento de barramento reflete em $7 \%$ dos óbitos totais da amostra analisada.

Tabelo 1 - Acidentes ampliados na mineração chinesa de carvão mineral com mais de cem óbitos, análise de 1949 a 2009

\begin{tabular}{|c|c|c|c|c|c|}
\hline EVENTO ACIDENTAL & NÚMERO DE EVENTOS & \% EVENTOS & ÓBITOSTOTAIS & \%ÓBITOS & ÓBITOS POR EVENTO \\
\hline Explosão por Gases Inflamável & 10 & $38 \%$ & 1.436 & $34 \%$ & 144 \\
\hline Explosão por Gases e Poeiras de Canão Inflamável & 7 & $27 \%$ & 931 & $22 \%$ & 133 \\
\hline Explosão por Poeiras de Canão Inflamável & 5 & $19 \%$ & 1.182 & $28 \%$ & 236 \\
\hline Incêndio & 1 & $4 \%$ & 110 & $3 \%$ & 110 \\
\hline Rompimento de Barragem & 1 & $4 \%$ & 276 & $7 \%$ & 276 \\
\hline$\overline{\overline{T O T A L} \text { GERAL }}$ & $\overline{26}$ & $\overline{100 \%}$ & 4.228 & $100 \%$ & 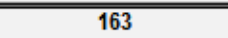 \\
\hline
\end{tabular}

Fonte:elaborada pelos autores (2020) com base em Lirong et al. (2009) 
3 Banco de dados com registro de falhas e eventos adversos significativos em todos os componentes envolvidos na deposição e armazenamento de rejeitos minerais. $O$ ímpeto original para a criação do compilado é fomentar recurso significativo de dados para análise de tendências, causas e consequências. Pode ser gratuitamente acessado na rede, desde que reconheça os créditos autorais com referência: Disponível em: https:// worldminetailingsfailures. org. Acesso em: 5 ago. 2021.

40 índice de magnitude (Col c) indica a escala global de um rompimento de barragem, com base em: volume liberado, distância atingida e óbitos. A base referencial do índice é pertinente à década de 1991 a 2000 . A pontuação para cada componente é a razão não ponderada da medida do evento para a medida média da década referência. O memorial de cálculo do índice de magnitude ( $\mathrm{Col} \mathrm{c}$ ) é expresso por: $\Sigma$ (Volume Liberado $\left(\mathrm{m}^{3}\right) / 1.896 .653$ $\mathrm{m}^{3}$ ); (Distância Atingida $(\mathrm{km}) / 39 \mathrm{~km}$ ); ( $\mathrm{N}^{\circ}$ Óbitos / 14 óbitos). Onde os valores $1.896 .653 \mathrm{~m}^{3}, 39 \mathrm{~km}$ e 14 óbitos, são as respectivas médias de volume liberado, distância atingida e óbitos da década de 1991 a 2000, base de referência deste índice. Fonte: World Mine Tailings Failures.
Em um primeiro momento, especialmente sobre eventos de rompimento de barragens, sugere-se uma excepcionalidade diante das demais causas, porém conforme Freitas e Silva (2019) afirmam, são mais frequentes do que se imagina. Dados trazidos da World Mine Tailings Failures (WMTF) 3, que cobrem um período de aproximadamente IOo anos (I9I5 a 2019), com um total de 356 registros, evidenciam, através da Gráfico 4, um crescimento dos eventos, principalmente a partir da década de I960. Com referência aos óbitos registrados, nota-se que a ascendência acompanha os números de falhas ao longo dos anos I960, com uma posterior redução nas décadas seguintes, porém com elevação a partir dos anos I990, sendo também incrementada a relação de falhas muito graves e graves perante as demais.

Gráfico 4 - Ocorrência de rompimentos de barragens e óbitos por década e registrados no WMTF entre 1915 e 2019

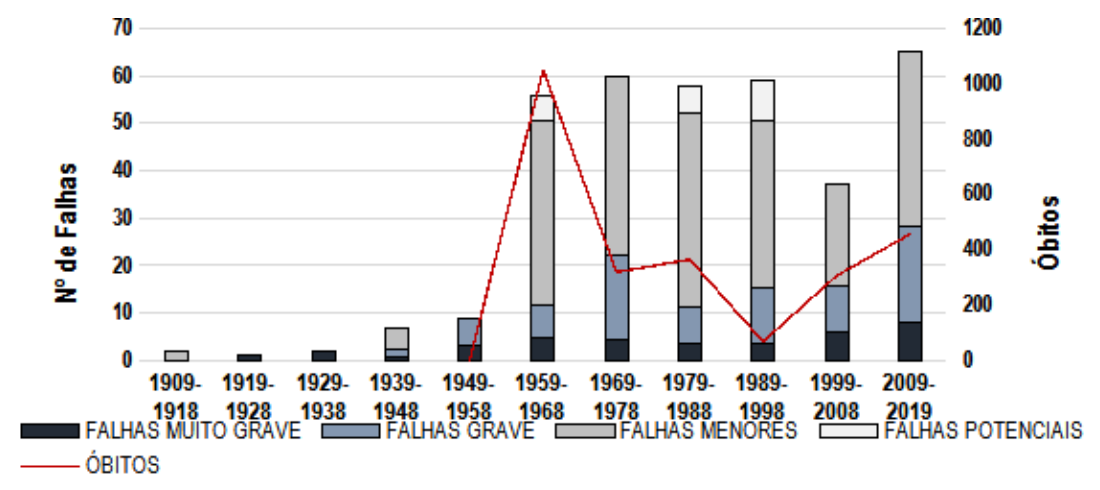

Fonte: elaborado pelos autores (2020) a partir de World Mine Tailings Failures (2019) e Freitas e Silva (2019)

A partir da seleção referencial do percentil 95 dos maiores índices de magnitude Col c4 das ocorrências de rompimento de barragens da base de dados WMTF, podemos verificar, através da Tabela 2, que ao longo dos últimos anos esses tipos de evento são relativamente recorrentes e de alto potencial de vitimização. De forma alarmante, Bowker e Chambers (2015), em um estudo dos modos de colapso em sistemas de barragens de mineração e análise dos eventos entre anos de I990 a 20I0, confirmam a ascensão da proporção de falhas graves e muito graves nas décadas mais recentes, evidenciando que a incidência desses eventos está se tornando cada vez mais frequente. 
Tabela 2 - Acidentes ampliados de maiores magnitudes envolvendo barragens de mineração. Registros entre os anos 1915 e 2019

\begin{tabular}{|c|c|c|c|c|c|c|c|}
\hline $\begin{array}{c}\text { ÍNDICE } \\
\text { MAGNITUDE } \\
\text { (Col c) }\end{array}$ & OPERAÇÃO MINERA & PAís & MINÉRIO & ALTEAMENTO & $\begin{array}{c}\text { VOLUME } \\
\text { LIBERADO }\left(\mathrm{km}^{3}\right)\end{array}$ & óBitos & ANO \\
\hline$\overline{41,4}$ & $\begin{array}{l}\text { Samarco | Barragem de Fundão } \\
\end{array}$ & Brasil & $\overline{\mathrm{Fe}}$ & $\overline{\text { Montante }}$ & 45.000 & $\overline{19}$ & 2015 \\
\hline 35,3 & Mina de Mir | Sgorigrad & Bulgária & $\mathrm{Pb} \mathrm{Zn}$ & Montante & 450 & 488 & 1966 \\
\hline 28,0 & Cómego do Feijão |VALE & Brasil & $\mathrm{Fe}$ & Montante & 12.000 & 270 & 2019 \\
\hline 21,7 & Los Cedros, Tlalpujahua, Michoacán & México & $\mathrm{AuAg}$ & Montante & $\mathrm{N} / \mathrm{l}$ & 300 & 1937 \\
\hline 19,5 & Mina Prestavel Mine | Mineração Prealpi & Itália & $\mathrm{F}$ & Montante & 200 & 269 & 1985 \\
\hline 18,3 & Tahsan | Mining Co. Taoshi & China & $\mathrm{Fe}$ & Montante & 268 & 254 & 2008 \\
\hline 18,3 & Huogudu | Yunnan Tin Group Co. & China & Sn & Montante & 11.356 & 171 & 1962 \\
\hline 17,0 & Tubu, N 2 Tailings | Padcal (Philex) & Philipinas & $\mathrm{Cu}$ & $\mathrm{N} / \mathrm{l}$ & 32.243 & 0 & 1992 \\
\hline 15,6 & El Cobre Old Dam & Chile & $\mathrm{Cu}$ & Montante & 1.900 & 200 & 1965 \\
\hline 12,6 & Imperial Metals | Mt Polley & Canadá & $\mathrm{CuAu}$ & Linha de Centro & 23.600 & 0 & 2014 \\
\hline 10,8 & Buffalo Creek | Pittson Coal Co. & EUA & Carvão & $\mathrm{N} / \mathrm{I}$ & 500 & 125 & 1972 \\
\hline 10,4 & Aberfan Colliery & Pais de Gales & Carvão & $\mathrm{N} / \mathrm{I}$ & 162 & 144 & 1966 \\
\hline 8,9 & Bafokeng | Morensky Tailings dam & Africa do Sul & $\mathrm{Pt}$ & Montante & 13.000 & 13 & 1974 \\
\hline 8,2 & Hpakant & Myanmar & Jade & $\mathrm{N} / \mathrm{I}$ & $\mathrm{N} / \mathrm{I}$ & 115 & 2015 \\
\hline 7,8 & Cities Service Phosphate & EUA & $\mathrm{P}$ & $\mathrm{N} / \mathrm{I}$ & 9.000 & 0 & 1971 \\
\hline 6,9 & Padcal N N 3-(Philex) & Philipinas & $\mathrm{AuCu}$ & Montante & 13.000 & 0 & 2012 \\
\hline 6,5 & Certej Gold Mine & Romênia & $\mathrm{Au}$ & $\mathrm{N} / \mathrm{I}$ & 300 & 89 & 1971 \\
\hline 6,4 & Mufulira|Roan Consolidated Mines & Zâmbia & $\mathrm{Cu}$ & $\mathrm{N} / \mathrm{I}$ & 68 & 89 & 1970 \\
\hline
\end{tabular}

Fonte: elaborada pelos autores (2020) a partir de World Mine Tailings Failures (2019) e Freitas e Silva (2019)

Previamente, por meio do enfoque sobre acidentes ampliados nas indústrias químicas e petroquímicas, é possível afirmar que os eventos maiores em operações mineiras são uma singularidade. Entretanto, eles possuem frequências dignas de atenção. Segundo os estudos citados e através da análise da base do PUPAD e WMTF, tais eventos concernem a explosões e incêndios em minas subterrâneas, assim como rompimentos de barragens de rejeitos, com índice de mortalidade substancial em relação às outras indústrias.

\section{A observância das investigações anteriores como elemento modelador}

Os acidentes ampliados em solo brasileiro do triênio de 2017 a 2020 trouxeram à tona questionamentos acerca da segurança do setor mineiro. Constatamos que acidentes maiores não se caracterizam apenas na indústria da mineração, uma vez que os acidentes ampliados das operações químicas, petroquímicas e de transporte e armazenamento de substâncias perigosas são significativamente impactantes, tanto em números absolutos de eventos quanto em potencial de danos. Todavia, um estudo que busca resgatar a noção dos desastres ampliados de mineração assume relevância. 
Dessa forma, o propósito desse trabalho é estabelecer um modelo de aplicação teórico-conceitual para mitigação e redução de eventos ampliados na mineração, construído a partir de dois pilares: Análise de Acidentes Anteriores (AAA) e conceituação teórica sobre técnicas de gerenciamento de risco.

Para AAA, considerou-se a investigação de duas fontes distintas. Primeiramente, para uma maior abrangência dos processos de alto risco, utilizou-se a base de dados PUPAC. Visando suprir as lacunas informativas sobre os registros de acidentes ampliados na mineração, especialmente para os casos de falhas em barramentos, explorou-se a base de dados do WMTF, ambos citados anteriormente. O embasamento teórico será arquitetado sobre a literatura atual da temática, segundo estudos notáveis e processos aplicáveis à indústria da mineração.

\subsection{Um recorte sobre as motivações de acidentes ampliados}

Conforme elucidado por Tauseef, Abbasi e Abbasi (20II), AAA é um dos exercícios mais potentes e mais empregados para obtenção de insights e respostas sobre as motivações e as razões das quais os acidentes ocorrem na indústria. É trazido pelos autores que a "análise de acidentes passados fornece inestimável sabedoria da retrospectiva com as quais estratégias para prevenir acidentes futuros ou mitigar o impacto podem ser desenvolvidos".

São I.065 notificações com referência dos tipos de motivações dos acidentes presentes no PUPAD. Levantou-se, através do diagrama de Pareto, a relação entre as causas, os números de eventos registrados e os óbitos. O descritivo dos tipos de causas foi pautado de acordo com análise do autor sobre as breves descrições dos eventos presentes no banco de dados e definido a classificação, como se segue no Quadro I.

Quadro 1 - Descritivos das classificações do tipo de causa para análise baseados nos 1.065 registros na base PUPAD, com descrições e causas do acidente

\begin{tabular}{|c|c|c|}
\hline MOTIVAÇÃO & TIPO DE CAUSA & DESCRITIVO \\
\hline \multirow{4}{*}{ (1) EQUIPAMENTOS } & (1.1) ELÉTRICA & $\begin{array}{l}\text { Relativo a curtos-circuitos, dispositivos de proteção, eletrização, sobrecarga, fuga de corrente, sobretensão, } \\
\text { aterramento. }\end{array}$ \\
\hline & (1.2) MECÂNICA & Relativo a mecânica da fratura, estruturais, corrosão, fadiga, vibração, desgaste, sistemas de proteção. \\
\hline & $\begin{array}{l}\text { (1.3) PERDA DE FUNÇÃO I } \\
\text { CATASTRÓFICO }\end{array}$ & $\begin{array}{l}\text { Relativo ao sequenciamento catastrófico de eventos. Ocorrência em mais de uma etapa, referente aos lapsos } \\
\text { primários de e secundários de equipamentos, envolvendo múltiplos modos de falhas. }\end{array}$ \\
\hline & (1.4) VAZAMENTOS & Efeitos de fluxos e transferências de fluidos. \\
\hline $\begin{array}{l}\text { (2) FATORES } \\
\text { EXTERNOS }\end{array}$ & (2.1) METEREOLÓGICOS & Referente aos eventos naturais, como: terremotos, inundações, tsunamis, raios, deslizamentos de terra. \\
\hline
\end{tabular}


Quadro 1 - Descritivos das classificações do tipo de causa para análise baseados nos 1.065 registros na base PUPAD, com descrições e causas do acidente

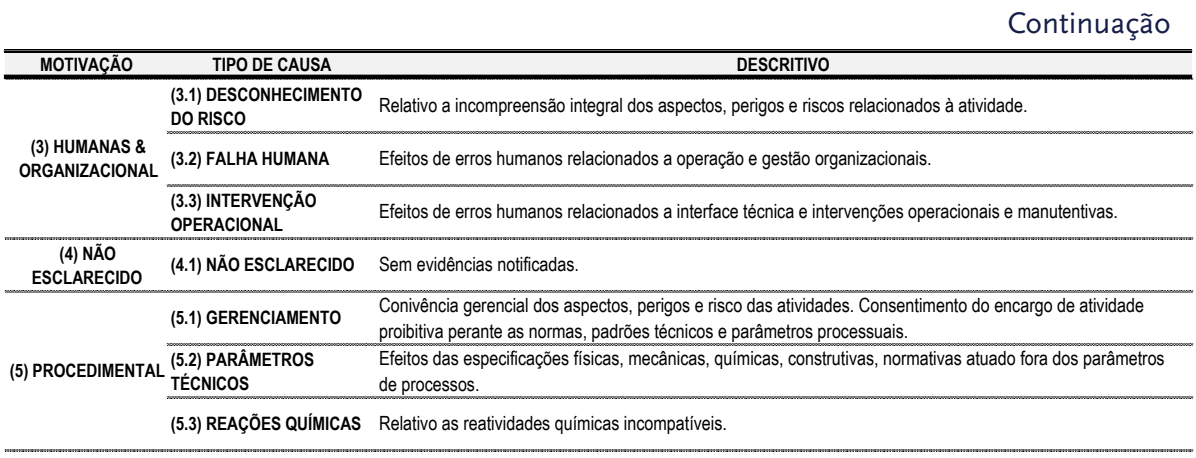

Fonte: elaborado pelos autores (2020) com base no PUPAD

Observa-se, no Gráfico 5, que 76\% dos acidentes registrados com descrições de causa são relativos aos itens:

- (I.3) Perda de Função/Catastrófico - 483 eventos classificados (48\%);

- (3.3) Intervenção Operacional - I62 eventos classificados ( $17 \%$ );

- (3.2) Falha Humana - I46 eventos classificados (I4\%).

Gráfico 5- Diagrama de Pareto para os tipos de causas relativos ao número de eventos, baseado nos 1.065 registros na base PUPAD, com descrições e causas do acidente

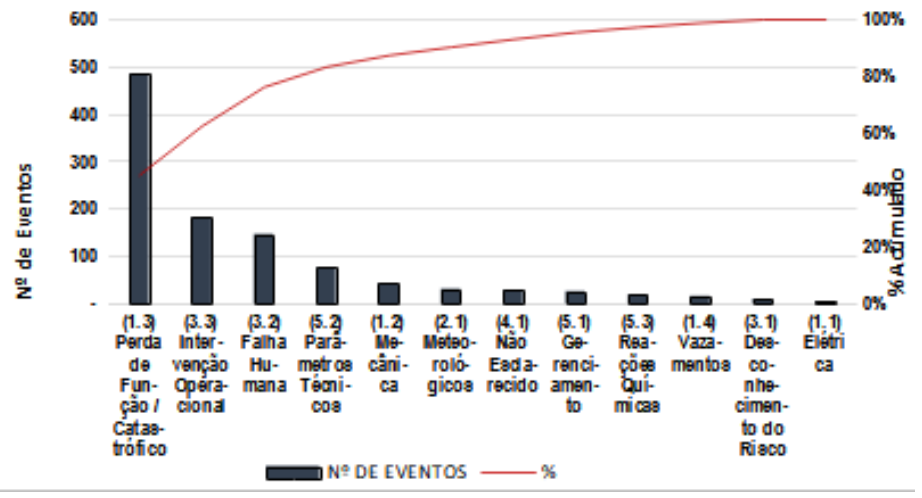

Fonte: elaborado pelos autores (2020) com base no PUPAD

Constata-se, no Gráfico 6, que 79\% dos óbitos registrados com descrições de causa ocorreram devido aos itens:

- (3.3) Intervenção Operacional - I.993 óbitos decorrentes (44\%);

- (I.3) Perda de Função/Catastrófico - 957 óbitos decorrentes (21\%);

- (3.2) Falha Humana - 585 eventos classificados (13\%). 
Gráfico 6 - Diagrama de Pareto para os tipos de causas relativos ao número de óbitos, baseado nos 1.065 registros na base PUPAD, com descrições e causas do acidente

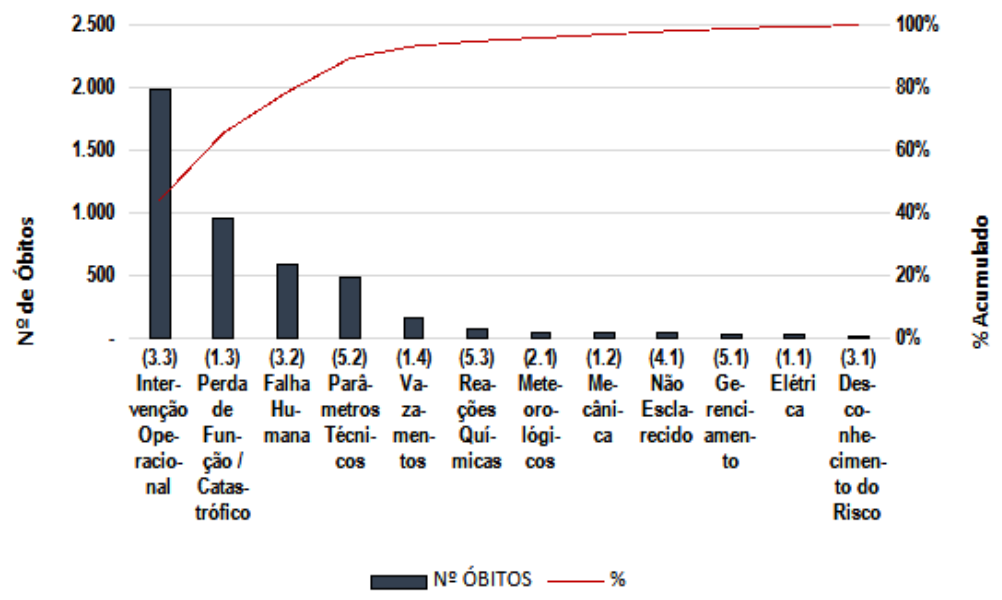

Fonte: elaborado pelos autores (2020) com base no PUPAD

A análise técnica estampa que os acidentes ocorrem devido a uma sucessão de falhas causadoras. Isso é verificado no item (I.3) Perda de Função/Catastrófico, presente no exercício do diagrama de Pareto, tanto em referência ao número de eventos, relativo a $48 \%$ das causas, quanto em número de óbitos, $21 \%$ das fatalidades. Pode-se extrair do descritivo que o sequenciamento catastrófico de eventos, devido a lapsos primários e secundários de equipamentos, envolvidos em múltiplos modos de falhas, é o maior causador de acidentes ampliados e o segundo em potencial de vitimização.

Em termos de número de óbitos relativos aos tipos de causa e tratando-se da capacidade em vitimar, temos em destaque o item (3.3), Intervenção Operacional, pertinente a $44 \%$ dos óbitos, segundo Gráfico 6. O exemplo trazido da base PUPAD da explosão em Neunkirchen, na Alemanha, em I933, ilustra bem esta motivação. Durante os reparos manutentivos em um gasômetro, uma faísca ocasionou uma explosão com mais de $70 \mathrm{~m}$ de altura. Foram 65 vítimas fatais, 90 feridos, I70 residências destruídas e mais de 700 habitantes da comunidade vizinha ficaram desabrigados. Apesar do episódio ser longínquo, possui referências bastante atuais. Em 20I8, na usina siderúrgica da Gerdau, em Ouro Branco (MG), cinco pessoas vieram a óbito e outras I2 tiveram ferimentos após uma explosão na coqueria da unidade, que também estava em uma intervenção de manutenção (BRASIL, 20I7). O que corrobora para as intervenções operacionais terem alto potencial de fatalidade é o fato de apresentarem uma 
minimização espacial e temporal do operador com a fonte de perigo, ou seja, a exposição é intrínseca, sendo qualquer falha crucial para o desencadeamento de um acidente.

Abreviando a análise, nota-se que os principais contribuintes para as causas de acidentes maiores apresentados nos diagramas de Pareto se intercalam nas primeiras posições, item (I.3) e (3.3), seguidos do item (3.2) Falha Humana, sendo esta vinculada a gatilhos como: não cumprimento procedimental, não percepção dos aspectos e perigos, treinamentos inadequados, controles de risco administrativos, comunicação e planejamento inadequado.

\subsection{Visão geral das motivações de acidentes em barragens de mineração}

Do ponto de vista dos acidentes ampliados, decorrentes do rompimento de barragens de mineração, expõe-se duas análises através do diagrama de Pareto para assimilação de causa e efeito, sendo: Gráfico 7: as causas notificadas relativas aos rompimentos; Gráfico 8: os tipos de alteamento em relação ao número de eventos. Ambos embasados de acordo com o registro do WMTF.

Gráfico 7 - Diagrama de Pareto para os tipos de causas relativos ao número de rompimento, baseado nos 356 registros na base WMTF, normatizados com descrições para causas do evento

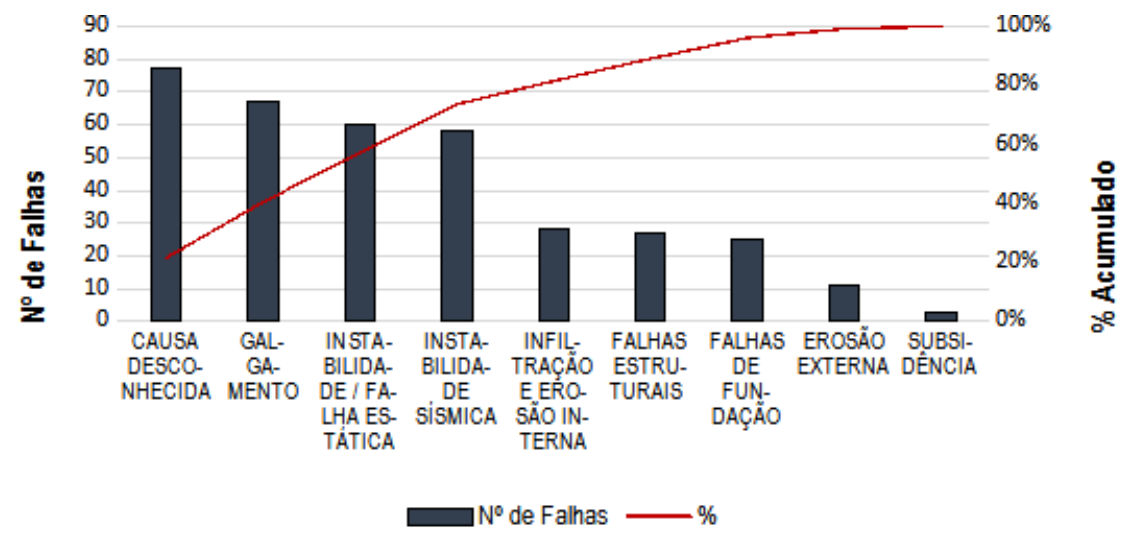

Fonte: elaborado pelos autores (2020) com base no WMTF 
Gráfico 8 - Diagrama de Pareto para os tipos de alteamento relativos ao número de rompimento, baseado nos 356 registros na base WMTF, normatizados com descrições para causas do evento

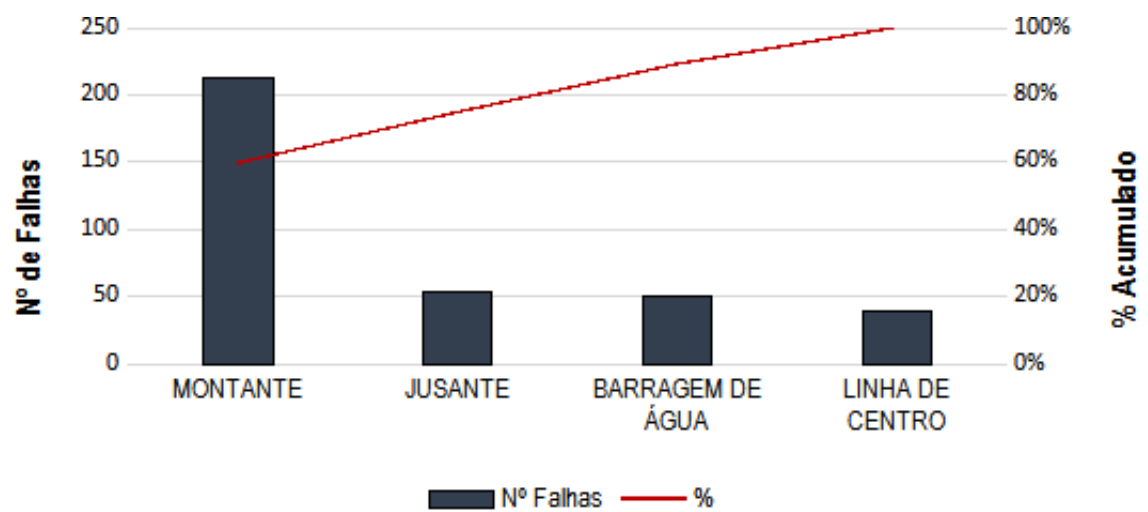

Fonte: elaborado pelos autores (2020) com base no WMTF

Em termos de qualificação das principais causas que ensejam os rompimentos de barramentos, pode-se concluir, de forma indistinta, visto que $22 \%$ das amostras não contemplam a descrição das causas, que os modos de falha mais presentes, tratando-se de mecanismos propulsores dos eventos em barragens, são:

- Galgamento (I9\%);

- Instabilidade/falha estática (I7\%);

- Instabilidade sísmica (16\%).

Do ponto de vista tecnológico de construção dos barramentos é evidenciado, dentro do espaço amostral, normatizado, da base de dados do WMTF, como os alteamentos a montante sobressaem em números absolutos de falhas em paralelo aos outros métodos. Contemplando 60\% das falhas notificadas. Em contraposição há o questionamento técnico do método a montante, seria de fato eficiente?

A fim de prosperar com o estudo das AAA, testou-se as correlações entre óbitos,

5 O coeficiente de Pearson mede o grau da correlação linear entre duas variáveis quantitativas. É um índice adimensional com valores situados ente $-1,0$ e 1.0 e reflete a intensidade relativa a dois conjuntos amostrais. altura do barramento e volume liberado, através do método de Pearson. ${ }^{5}$ Não sendo observado correlações entre os itens. Dessa forma, a conclusiva da análise é bastante ampla, porém, de fato, observa-se que o potencial de vitimização é relativamente alto. No espaço amostral do WMTF, encontram-se 365 notificações referente aos últimos I04 anos de coleta, deste total, em 309 registros (85\%) não houve nenhuma vítima fatal. Do restante, 47 registros contemplam pelo menos um óbito, sendo a média de mortalidade por eventos desta amostra de 6r óbitos por rompimento. Análise crítica 
do fato traduz que os maiores impactos, em termos de potencial de vitimização, estão no contexto espacial das vítimas, como por exemplo, localizações dentro das zonas de autossalvamento no momento do rompimento.

A confirmação da temática é exposta quando olhamos o recorte dos acidentes com mais de Ioo óbitos presente no WMTF. São dez eventos contabilizados, oito com tecnologia de alteamento a montante, média de 3,3 milhões de metros cúbicos liberados (relativamente baixo perante os atuais reservatórios), média de mortalidade de 233 óbitos por rompimentos e a ocorrência de I००\% das vítimas estarem a jusante dos eventos, dentro da área de autossalvamento, no momento do acidente.

\section{Das análises de acidentes anteriores e a proposta para um modelo contínuo de controle e gerenciamento de risco de sistemas passíveis de falhas}

A partir das análises do tópico anterior, as quais foram baseadas em motivações e atribuições causais, evidenciadas nas análises de dados do PUPAD e do WMTF, serão apresentadas as respectivas barreiras preventivas e mitigatórias de falhas, aliadas às propostas técnicas de gerenciamento de risco. O trabalho é restrito às análises fundamentadas no risco de vitimização humana causada por acidentes graves. Outros elementos de risco, como risco para ativos, negócio e risco para meio-ambiente estão fora do escopo. Vinculou-se diretamente às causas dos efeitos maiores de múltiplas indústrias ao estudo. A Figura I ilustra o diagrama de Ishikawa das causas principais e seus concernentes desdobramentos, resultado do compilado de investigação de acidentes ampliados, conforme explicitado. 
Figura 1 Diagrama de Ishikawa para as principais causas mapeadas que ensejam acidentes ampliados.

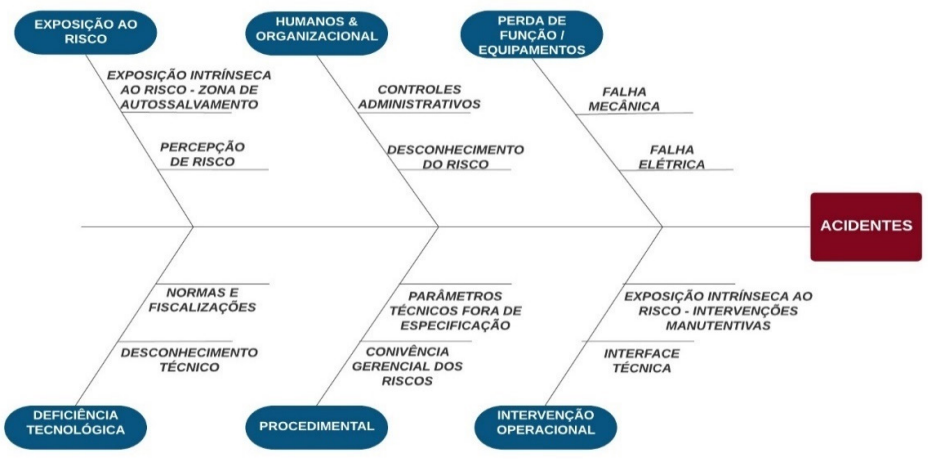

Fonte: elaborado pelos autores (2020) com base no WMTF

Observa-se um universo dos agentes causadores amplo, entretanto concentrado em áreas restritas do conhecimento e gerenciamento de risco, como: controles administrativos, passividades e deficiências tecnológicas, saúde dos ativos e disciplina operacional, gerencial e fiscal sobre os riscos conhecidos. E, em caráter não exaustivo, o desconhecimento do risco, que não sendo compreendido em sua total integralidade, inviabiliza qualquer medida preventiva e mitigadora de acidentes ampliados.

Segundo Kidam e Hurme (20I3), há casos em que a contribuição principal, por si só, é suficiente para instaurar e estabelecer o acidente. Entretanto, o desdobramento das causas traz subsídios significativos para o evento. O modelo elaborado por James Reason em I990, após análise circunstanciada de acidentes, respalda o entendimento trazido por Kidan. A estratégia Reason (I997), em seu modelo conhecido como queijo suíço, elucida o mecanismo de falhas e acidentes em sistemas complexos. A estrutura representativa propõe que todo perigo possui salvaguardas e que, na ocasião da transposição e alinhamento das lacunas entre as barreiras, há a ocorrência de perdas e acidentes.

As falhas ativas são os atos inseguros, cometidos pelas pessoas através de interferências diretas no sistema, e acionam eventos indesejados. Via de regra, possuem impactos momentâneos na integridade das barreiras. De acordo com a análise estatística das principais causas, apresentada no capítulo anterior, podemos exemplificar as falhas ativas por meio das intervenções operacionais manutentivas e operações fora dos parâmetros técnicos procedimentais. 
De acordo com Reason (2000), relativos às falhas latentes, há os “patógenos residentes" dentro do sistema, que surgem de exposições como decisões equivocadas tomadas por gestores e engenheiros, deficiências tecnológicas, procedimentos e normas técnicas falhas, controles administrativos e ativos não confiáveis. Cabe ressaltar que os mecanismos de fiscalização destituídos e escassos, aliados ao não conhecimento íntegro dos riscos envolvidos nas atividades, fortalecem e criam fendas nas falhas latentes.

Segundo Yang e Haugenb (20I8), pode-se considerar uma interpretação clássica tratar barreiras, sobretudo, como meios técnicos para impedir a progressão de uma fonte perigosa. São estratégias de controle comumente referidas como princípio de "defesa em profundidade" (IAEA, I999). Amparado no modelo de Reason (2000) e nos fundamentos causais dos acidentes ampliados levantados, a análise destaca-se promovendo quais seriam os modos de defesa investidos, assim como a delimitação para os papéis e responsabilidades dos agentes envolvidos na indústria mineira para um gerenciamento de risco coeso, racional e harmônico. A Figura 2 remete ao compilado das falhas mapeadas, barreiras de controle recomendáveis e mecanismo gerencial aplicável, apresentando o Modelo Contínuo de Controle e Gerenciamento de sistemas passíveis de falhas (MCCG), proposto neste trabalho.

Figura 2 Modelo Contínuo de Controle e Gerenciamento de sistemas passíveis de falhas voltado para acidentes ampliados na mineração

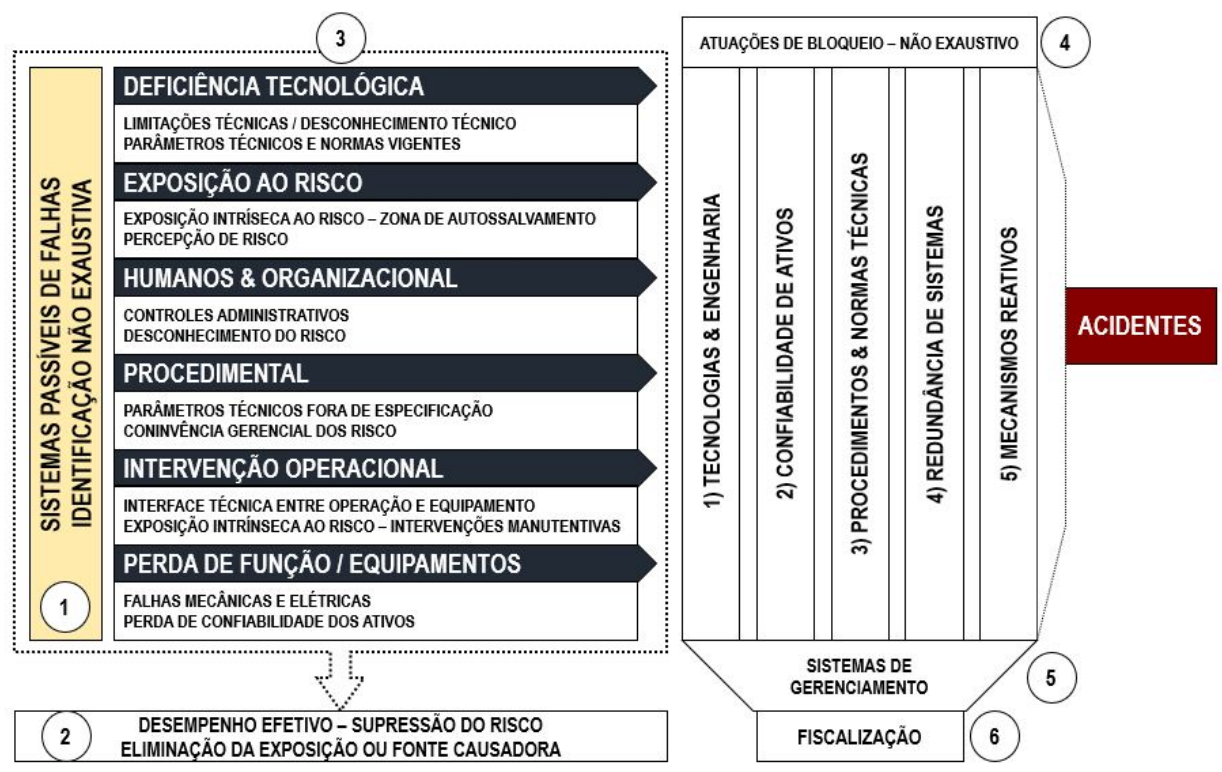

Fonte: elaborada pelos autores (2020) 
Esse modelo sugere, como primeira etapa (I), sob responsabilidade de gerenciamento de alto nível, o estabelecimento do contexto histórico como um mecanismo de observação e levantamento de perigos, riscos, aspectos e impactos referente aos riscos na indústria mineira, sendo necessário e mandatório o mapeamento não exaustivo dos riscos, que em muitas práticas são mapeados por matrizes de riscos alimentadas por protocolos padrões. Esta etapa é crucial para o processo, pois averígua onde ocorre as identificações das fontes potenciais de perigo. Deve-se ser revisitada em caráter periódico, assim como realizar análise de abrangência de acidentes anteriores similares à área. Observa-se que o fomento dos sistemas passíveis de falha originou-se das análises estatísticas das bases de informações PUPAD e WMTF, aqui identificadas.

De posse da identificação das fontes de ameaça, inicia-se a segunda etapa (2), com a adoção de uma estrutura técnica e científica de engenharia para aplicar o desempenho efetivo com a supressão do risco. A eliminação ocorrerá de forma eficiente, quando não houver exposição ou a fonte for neutralizada. Não sendo possível a anulação do risco, desdobra-se os sistemas passíveis de falhas identificados previamente, terceira etapa (3), com o objetivo de discernir os sistemas sujeitos às falhas ativas e latentes.

A quarta etapa (4), processo de atuação de bloqueios aos sistemas passíveis de falhas, deve ser desenvolvida iterativamente por equipe multidisciplinar, envolvendo equipe técnica de engenharia, fornecedores de novas tecnologias, centro de pesquisas, universidades, comunidades e benchmarking setoriais. Como modo de defesa primário, deve-se submeter preferencialmente, bloqueios e controles de engenharia, relativos a soluções tecnológicas voltadas para o risco. Para isso, é imprescindível o envolvimento com centros de pesquisa, desenvolvedores de tecnologias e soluções, parcerias com as universidades e, por fim, modelar-se diante dos benchmarkings existentes.

Como segunda atuação de bloqueio, deve-se encarregar da confiabilidade dos sistemas e da saúde dos ativos. A intervenção operacional é um dos fatores mais desencadeadores de grandes acidentes. Sendo assim, manter um comitê técnico de engenharia de confiabilidade voltado para ativos críticos, aliados às manutenções sistemáticas, é fundamental para garantia da salvaguarda.

Procedimentos e normas técnicas estabelecidos de acordo com os parâmetros de processos e requisitos legais vigentes irão formar a terceira atuação de bloqueio. As responsabilidades da execução dentro dos limites aceitáveis são estritamente da 
gestão do empreendimento, entretanto, as agências reguladoras devem auferir normas e requisitos que garantam os critérios e os fatores mínimos para a segurança das operações e das comunidades. A redundância de sistemas deverá compor a quarta atuação de bloqueio, no qual, se houver alinhamento prévio das lacunas nos três primeiros modos, este garantirá a segurança das operações.

Por fim, deve-se habilitar nos mecanismos reativos como quinta atuação de bloqueio. Capacitações e simulações persistentes, com todos os stakeholder, devem ser contempladas em cronogramas pela equipe técnica de engenharia e segurança do trabalho. Além disso, envolver atores externos é fundamental para a certificação da eficácia do sistema, assim como todas as atuações de bloqueio devem ser encaradas, compulsoriamente, como não exaustivas.

A quinta etapa (5) refere-se à governança e ao gerenciamento de risco. Portanto, diz respeito às certificações normativas, célula de gestão interna e auditorias para precaver o fluxo do executivo dentro do processo. Ademais, a sexta etapa (6) é de suma importância para blindagem, visto que, de responsabilidade de órgãos governamentais, as fiscalizações devem atuar incisivamente junto às operações para garantia dos requisitos legais.

Com o propósito de aplicar os conceitos do MCCG e mensurar o nível de atendimento das operações mineiras no modelo, desenvolveu-se um protocolo de utilização baseado em cinco elementos, sendo: (I) ESTRUTURA: trata-se da compreensão dos tópicos relacionados à governança, à organização, à concepção e à integração dos elementos essenciais que compõem o corpo de gestão de riscos; (II) PROCESSOS: comporta-se às alíneas relacionadas à identificação, à avaliação e ao tratamento de riscos, assim como aos aspectos de gestão de processos; (III) TECNOLOGIA: trata-se do conjunto de técnicas e métodos empregados para o desempenho efetivo do risco, ou seja, eliminação do perigo ou da exposição, e do desempenho reativo, no qual considera-se os itens de controle e mitigação do impacto; (IV) SISTEMAS DE GERENCIAMENTO: é o elemento do modelo que integra as disciplinas de planejamento, organização, controle e monitoramento; (V) SISTEMAS TÉCNICOS E RESULTADOS: contempla os aspectos relacionados ao desempenho e à evolução dos resultados do processo de gerenciamento de riscos, tendências, atendimento a prazos e critérios dos planos de metas, requisitos e expectativas previamente definidos. 
Para aplicação do protocolo qualifica-se o atendimento em quatro aspectos, sendo: INEXISTENTE: o subitem não é atendido; INFERIOR: existe o conceito e a prática do subitem em caráter primário, sendo necessário tempo e/ou recursos para o atendimento e o desenvolvimento da maturidade; EXISTENTE: observa-se o conceito e a prática do subitem, porém não em sua plenitude e/ou com a maturidade ainda em fase de desenvolvimento; ATENDIMENTO PLENO: o subitem é atendido em sua plenitude, com observação de maturidade dentro do elemento. A Figura 3 ilustra o processo de qualificação do nível de atendimento aos itens de cada elemento.

Figura 3 Nível de atendimento e qualificação aos itens do protocolo do Modelo Contínuo de Controle e Gerenciamento de Sistemas Passíveis de Falhas.

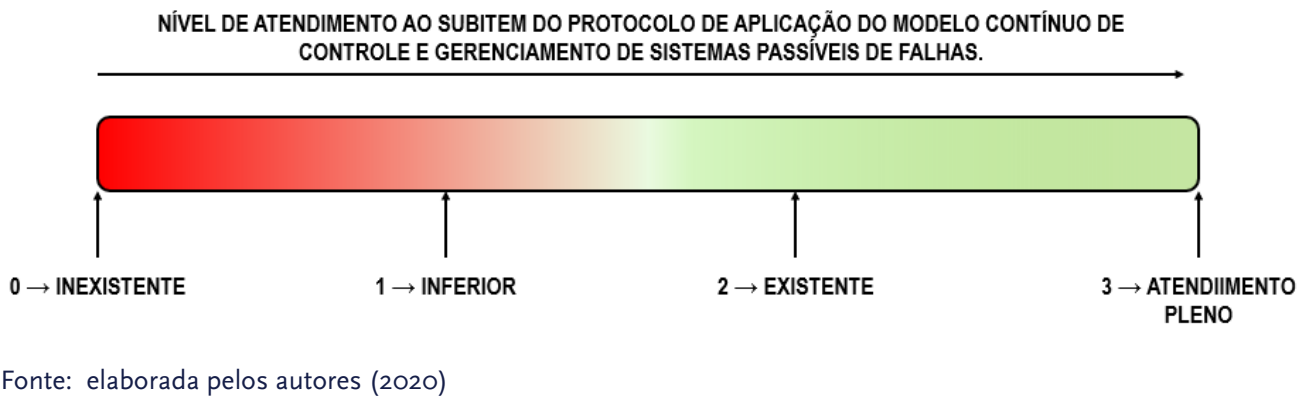

Os elementos são examinados e qualificados por meio das pontuações de atendimentos ao protocolo do MCCG. Obtém-se o resultado quantificado por meio de uma régua métrica percentual de cada elemento, como evidenciado na Figura 4.

Figura 4 Nível de atendimento e qualificação aos itens do protocolo do Modelo Contínuo de Controle e Gerenciamento de Sistemas Passíveis de Falhas.

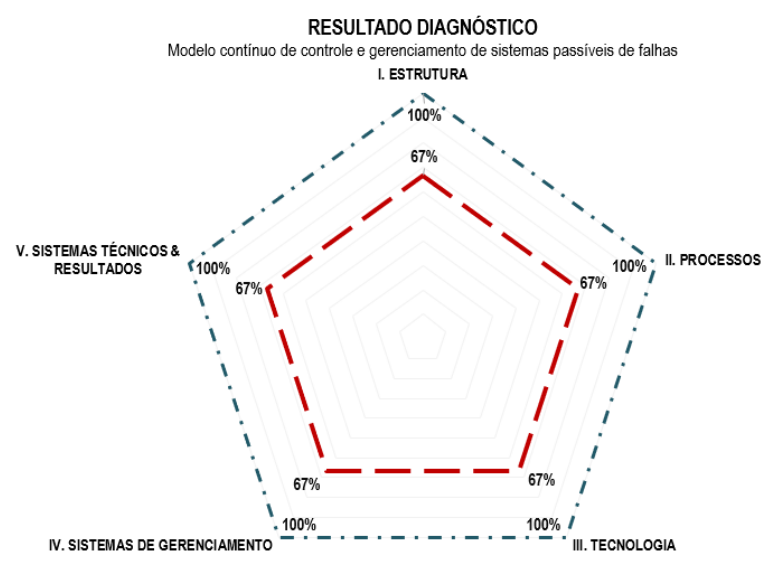

Fonte: elaborada pelos autores (2020) 
Em princípio, o potencial de uma organização, em sua plenitude, de gerenciamento, mitigação e controle de risco é alcançado quando se obtém Io०\% de atendimento na métrica do MCCG. Entretanto, por meio das premissas teóricas e conceituais aqui apresentadas, trata-se a métrica de $67 \%$ de atendimento como limítrofe mínimo de segurança exigido para prevenção e gerenciamento dos riscos maiores, face ao fato de representar a aplicação estruturada de controles aos sistemas passíveis de falha, mesmo reconhecendo-se pela aplicação da metodologia, haver potencial de melhoria.

Desta forma, as organizações e os seus stakeholders precisam se autodiagnosticar e promover as condições necessárias para elevar os níveis de atendimento até a plenitude do MCCG, sugerindo-se o uso do protocolo desenvolvido pelos autores, para esta finalidade. O protocolo ${ }^{6}$ está disponibilizado, em link, para o uso da comunidade mínero-metalúrgica e acadêmica.

\section{Considerações Finais}

Uma análise dos números industriais evidenciou o lamentável fato de que acidentes ampliados são uma realidade no meio industrial há dezenas de anos, sendo impulsionados, principalmente, pelos eventos da indústria química e petroquímica. Entretanto, a mineração marca presença negativa no ranking. O setor de exploração de carvão mineral alavanca a taxa de mortalidade, sendo a maior observação da amostra. Explosões em minas subterrâneas, decorrentes de gases e poeiras inflamáveis, contribuem com o número. Rompimentos de barragens de rejeitos não são uma singularidade da mineração brasileira, havendo uma excelente oportunidade de aprendizado com o passado. Nos desastres resultantes de barragens que mais vitimaram, todos as vítimas estavam no momento do colapso, a jusante ao barramento, na zona de autossalvamento.

Ademais, observamos que as principais motivações causadoras dos acidentes ampliados são: deficiência tecnológica, exposição intrínseca ao risco, falhas humanas e organizacionais, intervenções operacionais e perdas de função de equipamentos. Todas, se não passíveis da supressão do risco, como presenciamos as atuais descaracterizações de barragem com alteamento a montante, são gerenciáveis através do modelo proposto.
6 O protocolo de aplicação do Modelo Contínuo de Controle e Gerenciamento de Sistemas Passíveis de Falhas, voltados para acidentes ampliados, tem como objetivo apoiar a comunidade acadêmico-científica e os empreendimentos míneros-metalúrgicos na compreensão das práticas de gerenciamento de riscos e prevenção das perdas. Os autores autorizam a reprodução total e parcial deste trabalho, por qualquer meio convencional ou eletrônico, para fins de estudo, pesquisa ou em caráter profissional deste que citada a fonte. O protocolo está disponível em: https:// drive.google.com/drive/ folders/1zKblhADvXch_Kk 4SymmaQE2fel8iQTey?usp =sharing 
As organizações devem se autodiagnosticar, e os atores e os stakeholders devem promover as condições necessárias para o atendimento do limítrofe mínimo do MCCG aqui proposto. Por fim, não cabe a nós, por meio deste trabalho, julgar as motivações anteriores que levaram a cenas lamentáveis na mineração, porém o estudo resgata a noção dos desastres ampliados e a importância de se aprender com o passado para gerir o futuro de forma segura e produtiva. Neste sentido, acreditamos que a aplicação da tecnologia do MCCG na prática permitirá seu refinamento e a elaboração de trabalhos futuros visando o seu aprimoramento e o progresso das disciplinas de gestão de riscos. 


\section{Referências}

BARCELLOS, C. et al. Avaliação dos Impactos sobre a saúde do desastre da mineração da Vale (Brumadinho, MG). Instituto de Informação e Comunicação Científica e Tecnológica em Saúde (ICICt/Fiocruz), 20I9. Disponível em: https:// www.arca.fiocruz.br/bitstream/icict/32268/3/Nota_Tecnica_Brumadinho_ impacto_Saude_oro220I9.pdf. Acesso em: r jul. 2020.

BOWKER, L.; CHAMBERS, D. The risk, public liability a economics of tailings. Stonington: [s.e.], 2015 .

BRASIL. Congresso. Câmara dos Deputados. Relatório sobre acidente na Usina da Gerdau em Ouro Branco - Minas Gerais. Câmara dos deputados, 20I7. Disponível em: https://www.camara.leg.br/propostas-legislativas/2I64534. Acesso em: 22 abr. 2020.

CAMPOS, P. H. A. et al. Health and Safety in Brazilian Mines: A Statistical Analysis. In: INTERNATIONAL SYMPOSIUM ON MINE PLANNING AND EQUIPMENT SELECTION (MPES), 28., 20I9. Proceedings... MPES, 2019.

CANDIAN, R. C. et al. Análisis de la accidentalidad por caída de rocas en la minería de los Estados Unidos de Norte América. In: CONGRESSO IBEROAMERICANO EN MINERÍA SUBTERRÁNEA Y A CIELO ABIERTO UMINING, 2., Santiago de Chile, 20I8. Anais... 2018.

CAROL, S., VILCHEZ, J.A., CASAL, J. Study of the severity of industrial accidents with hazardous substances by historical analysis. Journal of Loss Preventin in the Process Industries, Centre d'Estudis del Risc Tecnològic (CERTEC), Department of Chemical Engineering, Universitat Polotècnica de Catalunya ETSEIB, v. I5, p. 5I7-524, 2002.

CONSELHO DA UNIÃO EUROPEIA. Directiva do Conselho de 24 de junho de 1982 relativa aos riscos de acidentes graves de certas actividades industriais (82/501/ CEE). Luxemburgo: Jornal Oficial das Comunidades Europeias, n. L 230/I, I982. Disponível em: https://op.europa.eu/pt/publication-detail/-/publication/ bb2Irber-2448-4e7c-bfc5-Id3363If3dbe/language-pt. Acesso em: I jul. 2020.

EVAN, W. M.; MANION, Mark. Minding the Machines: Preventing Technological Disasters. Upper Saddle River (USA): Prentice Hall PTR, 2002. 
FREITAS, C. M.; PORTO, M. F. S.; MACHADO, J. M. H. Acidentes industriais ampliados: desafios e perspectivas para o controle e a prevenção. Rio de Janeiro: Editora FIOCRUZ, 2000.

FREITAS, C. M; SILVA, A. S. Acidentes de trabalho que se tornam desastres: os casos dos rompimentos em barragens de mineração no Brasil. Rev. Bras. Med. Trab., v. I7, n. I, p. 9-21, 2019.

IAEA - International Atomic Energy Agency. Basic Safety Principles for Nuclear Power Plants 75-INSAG-3. Report INSAG-I2. Vienna: International Nuclear Safety Advisory Group, I999.

IPHECA - International Programme on the Health Effects of the Chernobyl Accident. Health consequences of the Chernobyl accident, results of the IPHECA pilot projects and related national programmes: summary report. Geneva: World Health Organization, I995. Disponível em: https://apps.who.int/iris/bitstream/ handle/I0665/4I80I/924I56I8I5_eng.pdf?sequence=I\&isAllowed=y. Acesso em: 2 abr. 2020.

KIDAM, K.; HURME, M. Statistical Analysis of Contributors to Chemical Process Accidents. Chem. Eng. Technol., v. 36, n. I, p. I67-I76, 2013.

LIRONG, W. et al. Major accident analysis and prevention of coal mines in China from the year of I949 to 2009. Mining Science and Technology, China, v. 2I, issue 5, p. 693-699, set. 2011 .

REASON, J. Human Error. New York: Cambridge University Press, I990.

REASON, J. Managing the Risks of Organizational Accidents. Hants (England): Aldershot; Brookfield (USA): Ashgate, I997.

REASON, J. Human error: models and management. BMJ. Br. Med. J., v. 320, 768-770, 2000.

TAUSEEF, S. M.; ABBASI, T.; ABBASI, S. A. Development of a new chemical process-industry accident database to assist in past accident analysis. Journal of Loss Prevention in the Process Industries, Elsevier, p. 426-43I, $201 \mathrm{I}$.

UNEP - United Nations Environment Programme. Chemical Pollution: a global overview. Geneva: UNEP, I992. 
WORLD MINE TAIINGS FAILURES. World mine tailings failures-from I9I5. World Mine Tailings Failures, 20I9 [on-line]. Disponível em: https:// worldminetailingsfailures.org/. Acesso em: 20 abr. 2020.

YANG, X.; HAUGEN, S. Implications from major accident causation theories to activity-related risk analysis. Safety Science, v. IOI, p. I2I-I34, jan. 20I8. Disponível em: https://doi.org/ıo.IoI6/j.ssci.2017.08.020. Acesso em: 22 abr. 2020. 